\title{
Kansei approach for the design of functional products for the elderly
}

\section{Kuo-Hsiang CHEN}

Shou University

Ching-Chien LIANG

University of Kang Ning

Ya-Hsueh LEE

Southern Taiwan University of Science and Technology

Po-Hsiang PENG

Jia-Xuan HAN

National Cheng Kung University

\begin{abstract}
Based on the theory of Kansei engineering, this study adopts the methods and steps of user research and divides the whole process into three stages: (1) survey and categorization of functional household items for the elderly; (2) interview with the high-involvement elderly regarding their affective preference; (3) questionnaire survey and statistical analysis of the representative functional household item for the elderly. Early results showed that (1) in terms of product search ratio, mobility assisting and communication products have the highest proportion; (2) in terms of product sales ratio, mobility assisting products reaches $25 \%$ and footwear products are the highest among them; (3) interviews with high-involvement elderly show that footwear with $40.8 \%$ is the highest demand among functional household items. Therefore, footwear products will be used as example to conduct subsequent study on Kansei preference and affective design for the elderly.
\end{abstract}

Keywords: Kansei Engineering, Functional Products, Elderly, High-involvement, Affective Design

\section{Introduction}

The new wave of retired elderly people are mostly heavily dependent on scientific gadgets in the era of science and technology. Their living style, including diet, social activities, sports and leisure, education and entertainment, etc., is very worthy of further study. In recent years, the demand for elderly products has grown rapidly due to the growth of the 65year-old population. The elderly consumer market has become the main source of consumer economy. In the book on consumer behavior in the super-aged society, Hiroyuki Murata (2015) mentioned that the products designed for elderly market need to address the "three-troubled" for the elderly, namely, "unease", "dissatisfaction", and "inconvenience". Lee and Kuo (2001) suggested that the needs of the elderly vary depending on their daily life style. Those who are active and like to exercise prefer learning, socializing, and trying new things; therefor, they spend most of the time on learning the operation of new products. For relatively passive elderly, they focus more on material aspects, such as "food", "clothing", and "pleasure". As for those who do not like exercise or with poor health, their needs focus on "food", "clothing", "live", and "transport". This study based on the survey of elderly people life styles and product use, summarized the demand of functional products in everyday life for high-involvement elderly groups.

\section{Methods and Procedure}

Survey of daily necessities classification for the elderly 
This study first searched and classified products related to food, clothing, live, transport, education, and entertainment for the elderly. However, due to the number of elderly related products are so huge, the research object mainly focused on the screening results from the database of Resource Portal of Assistive Technology (RPAT) for Multifunctional Assistive Technology, Social and Family Affairs Administration, Ministry of Health and Welfare. Based on the amount of daily search number, we screened the top 9 categories of daily necessities.

According to the product listed on RPAT database, we can see that the mobile assistive products category is the most searched for one, ranked number one as it has three products on the top ten search charts. Leisure products category ranked the second with two products on the list; and personal cleaning products came as the third with one product on the list. Therefore, mobile assistive products were used as samples for the study in the next stage. The product rankings are shown in Table 1. Mobile assistive products are searched frequently by elderly person, such as walking sticks, crutches, walkers, four-leg crutches, trolleys, wheelchairs, electric scooters, electric wheelchairs and so on.

Table 1. Short list of common elderly household items from RPAT database

\begin{tabular}{|l|l|l|}
\hline \multicolumn{1}{|c|}{ Categories } & Description & Ranking \\
\hline 1. eating & $\begin{array}{l}\text { Special tablew are, suchas: curved, easy to scoop plate, non-slip mat, gap cup, } \\
\text { adjustable w eighted easy to hold tablew are, one-way straw, etc. }\end{array}$ & 7 \\
\hline 2. hy giene & Socks aids, shoelace swivel, slippers aids, snap-onaids, zipper aids, dress aids, etc. & 6 \\
\hline 3. personal cleaning & $\begin{array}{l}\text { Personal cleaning, toilet, bath, toilet height, bath chair, bathtub armrest, multi-functional } \\
\text { bath set, hair-w ash sink, etc. }\end{array}$ & 3 \\
\hline 4. mobile assistive & $\begin{array}{l}\text { Cane, crutches, walkers, four-leg crutches, trolleys, wheelchairs, electric scooter, electric } \\
\text { wheelchair, etc. }\end{array}$ & 1 \\
\hline $\begin{array}{l}\text { 5. environmental } \\
\text { reminder }\end{array}$ & $\begin{array}{l}\text { Bathroom anti-slip strips, all kinds of safety handrails, automatic lighting systems, voice } \\
\text { warning system, high contrast ground, etc. }\end{array}$ & 8 \\
\hline $\begin{array}{l}\text { 6. labor-saving } \\
\text { products }\end{array}$ & $\begin{array}{l}\text { Electric scooter, remote control switch, radio called bell, effort saving handle, easy to } \\
\text { stand up mat, etc. }\end{array}$ & 9 \\
\hline $\begin{array}{l}\text { 7. communication } \\
\text { products }\end{array}$ & Degraded visual and auditory capability may cause some difficulties in communication. \\
\hline 8. footw ear & foot aids, such as insoleto reduce the pain, increase walking ability. & 4 \\
\hline 9. leisure products & $\begin{array}{l}\text { Large poker, card holder, large mahjong, automatic shuffer, indoor shooter, dartball, } \\
\text { indoor tennis, pillow audio, fitness ball, grip ball, etc. }\end{array}$ & 2 \\
\hline
\end{tabular}

The transport product samples come from Amazon, one of the world's leading e-commerce providers. The top 100 elderly products on the website are summarized as shown in Fig. 1.

Among the top 100 products in the sales volume, transport category with 25 items summed up the highest. Within the category, six sub-categories can be identified as: the footwear, socks, crutches, trolleys, electric cars, and wheelchairs (as shown in Fig. 2). Among them, footwear accounted for 7 items; crutches accounted for 6 items; trolleys and socks accounted for 4 items each; wheelchairs 2 items; and electric cars accounted for 1 item.

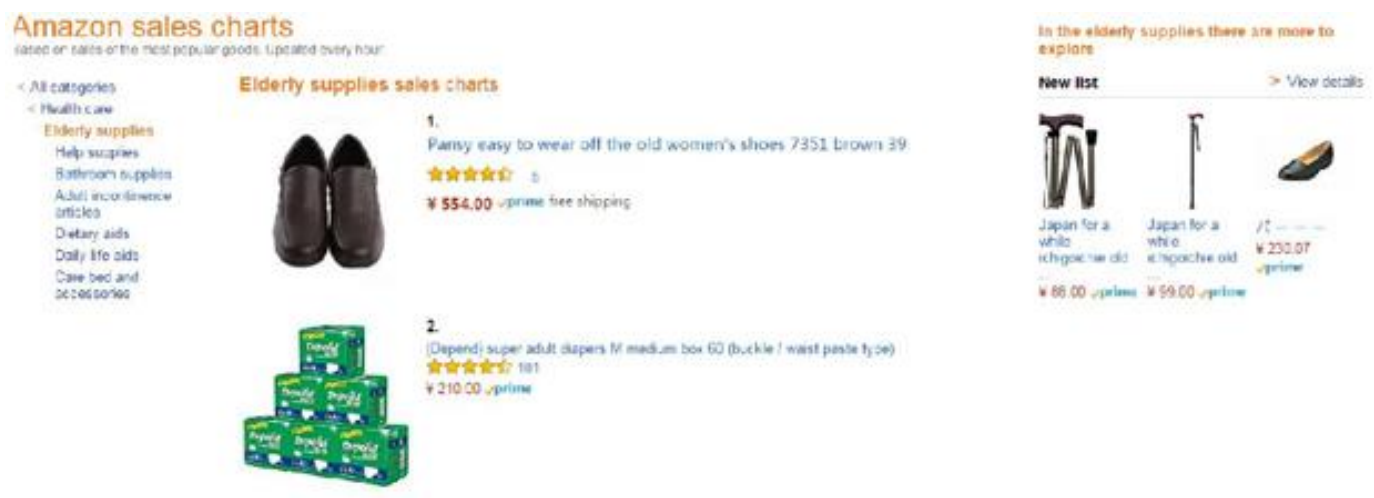




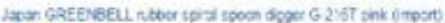

3

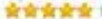

x\$5 Novime

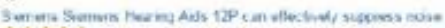

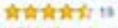

- 554 ar voime

Fig. 1. Elderly product sales charts of Amazon's website (Amazon.com Inc.)

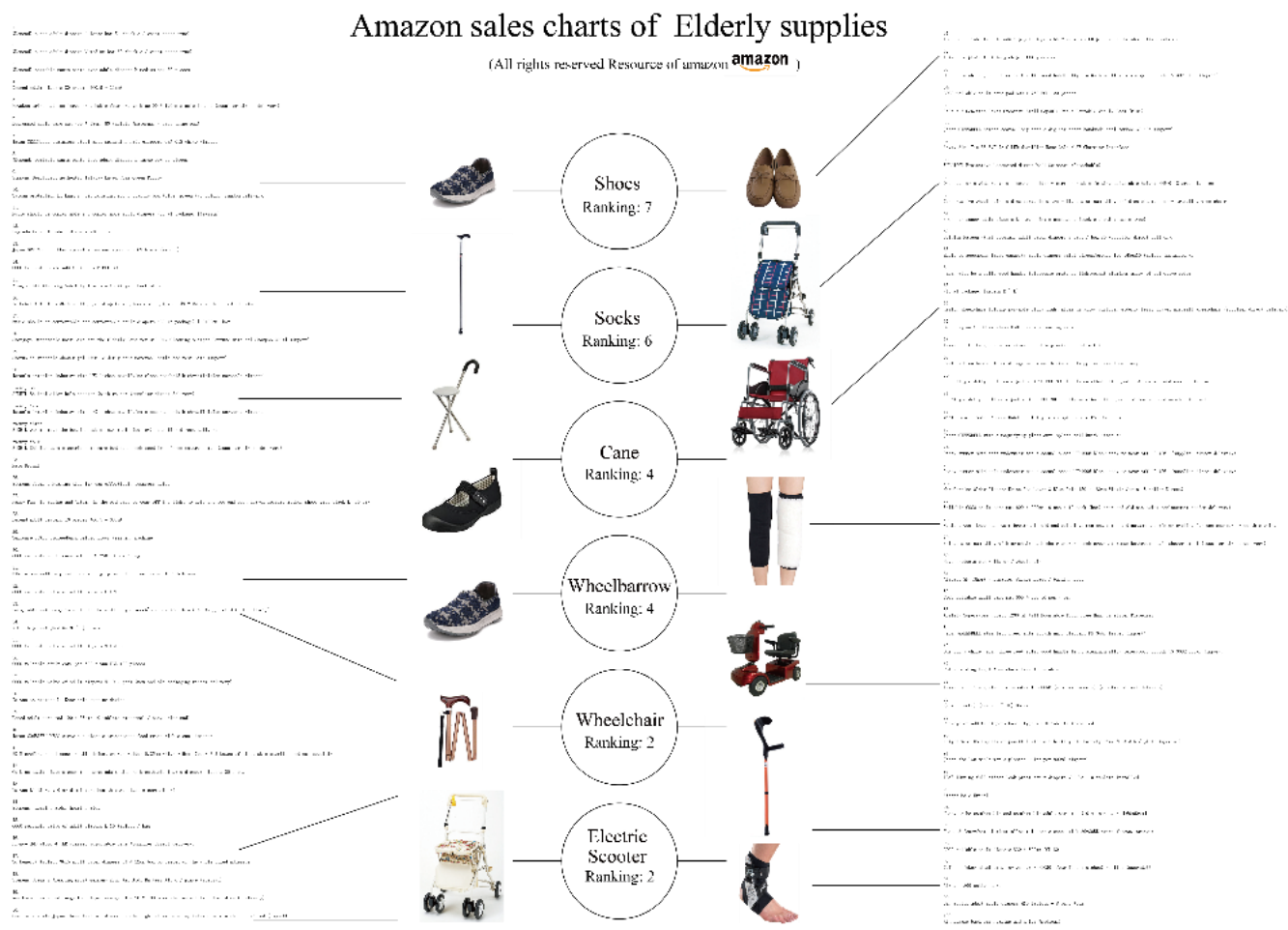

Fig. 2. Elderly transport goods ranking

Table 2 shows the products. Footwear sub-category with 7 items reached the highest sales on the list and was the most frequently purchased item.

Questionnaire interview on functional products with high-involvement elderly

Through double questionnaire surveys to make sure whether the footwear is the most commonly used functional products for the elderly.

The 25 samples used were screened from the website. A questionnaire survey on usage was conducted for the elderly (as shown in Fig. 3), followed by a questionnaire survey on the level of involvement for functional products for the elderly. The 
results will be used for the EGM interview in the next stage. Fig. 4 shows an online questionnaire for recruiting highinvolvement elderly in using functional products.

Table 2. Transport products for the elderly

\begin{tabular}{|c|c|c|c|c|c|}
\hline $\begin{array}{l}\text { Category } \\
\text { number }\end{array}$ & $\begin{array}{l}\text { Product } \\
\text { item }\end{array}$ & Number & images & Description & Amazon Ranking \\
\hline \multirow{7}{*}{1} & \multirow{7}{*}{ Shoes } & (1) & & $\begin{array}{l}\text { Pansy easy to w ear and take-off light } \\
\text { shoes }\end{array}$ & No. 15 \\
\hline & & (2) & & DUNLOP soft material cushion shoes & NO. 17 \\
\hline & & (3) & & Pansy summer anti-skid casual shoes & NO. 37 \\
\hline & & (4) & & Duflex healthy shoes & NO. 44 \\
\hline & & (5) & & Rider Brazilian fashion function slippers & NO. 59 \\
\hline & & (6) & & BaBa Baba GPS smart shoes & No. 72 \\
\hline & & (7) & & $\begin{array}{l}\text { IUMaw anti-skid easy to w ear and take- } \\
\text { off shoes }\end{array}$ & No. 83 \\
\hline \multirow{6}{*}{2} & \multirow{6}{*}{ crutches } & (8) & & $\begin{array}{l}\text { KAINOS carbon fiber material folding } \\
\text { O-ty pe anti-skid cane }\end{array}$ & NO. 12 \\
\hline & & (9) & & $\begin{array}{l}\text { MAKI standing assisted soft grip four- } \\
\text { leg cane }\end{array}$ & NO. 30 \\
\hline & & (10) & & Fuji home ty pe S folding crutches & NO. 48 \\
\hline & & 11) & & $\begin{array}{l}\text { KangChien aluminum alloy } \\
\text { crutchstool }\end{array}$ & NO. 59 \\
\hline & & 12) & & KangChien four-leg crutches & NO. 62 \\
\hline & & 13) & & $\begin{array}{l}\text { PengYi four-leg anti-slip } \\
\text { climbing sticks }\end{array}$ & 10. 63 \\
\hline
\end{tabular}




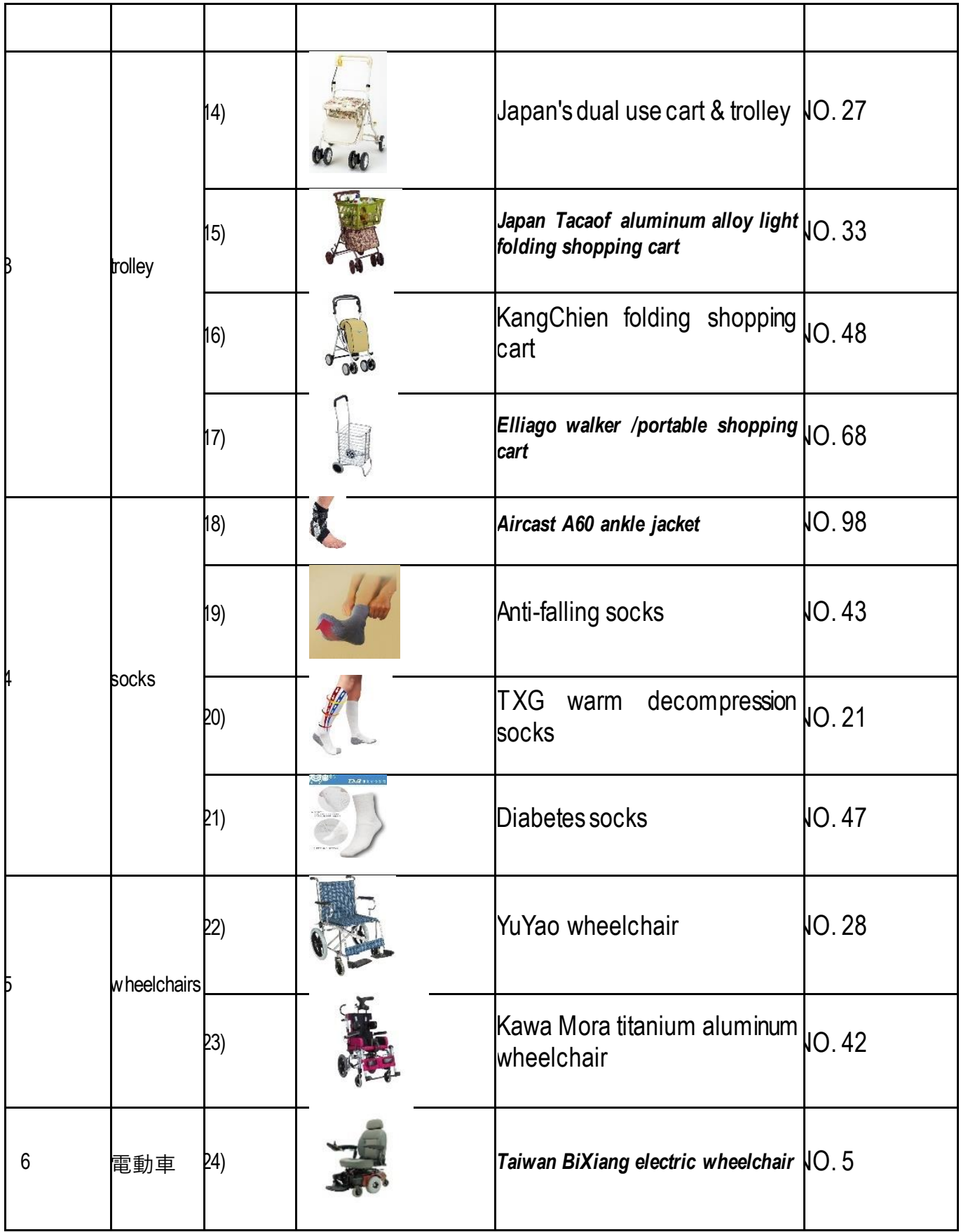



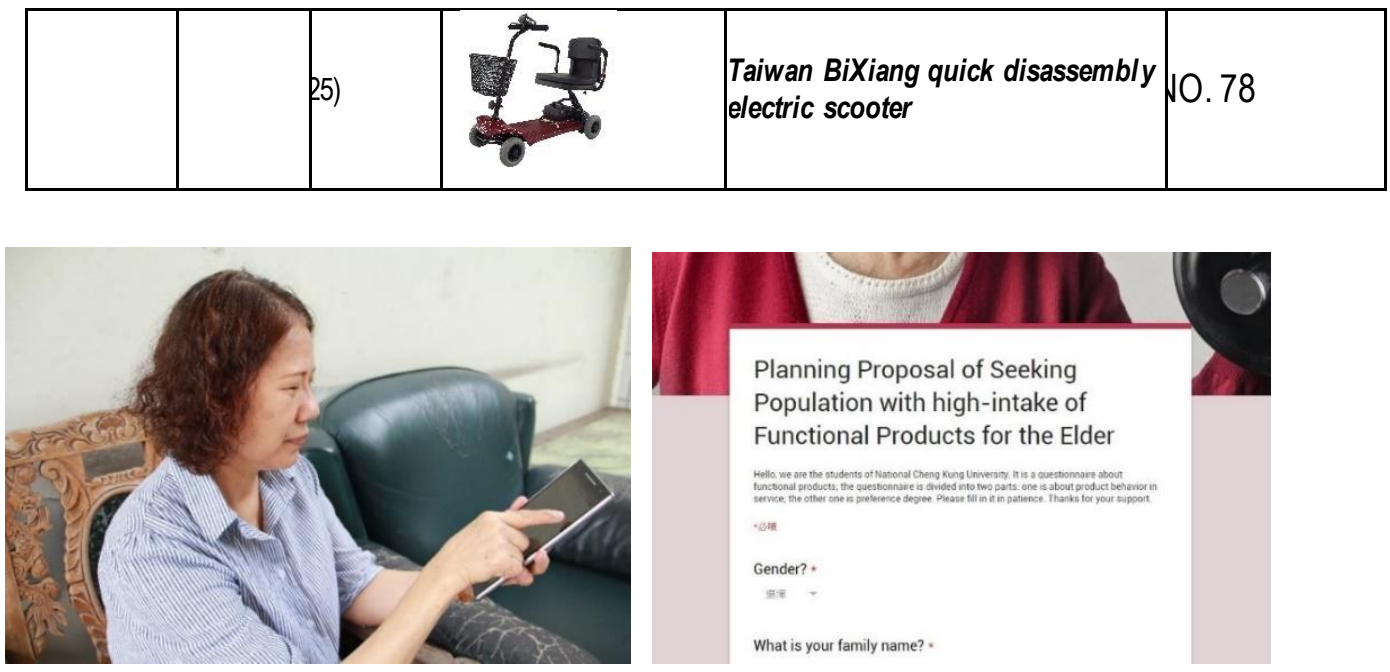

Fig. 3. Fill in the online questionnaire

Fig. 4. GOOLE online questionnaire design

Statistical analysis for the questionnaire on representative elderly functional products

Screened from the online questionnaire, 12 elderly people over the age of 65 were asked to attend the interview, and the results are shown in Fig. 5. Footwear products, with the highest percentage, took up to $40.8 \%$ meaning that it was used most frequently and by most subjects. Fig. 6 indicated that items labeled 1 to 7 are all footwear. Therefore, footwear will be used to represent the elderly daily functional products in the study.
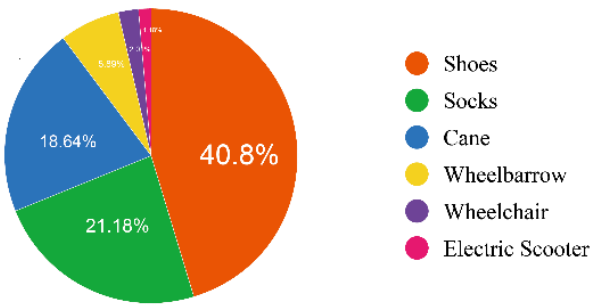

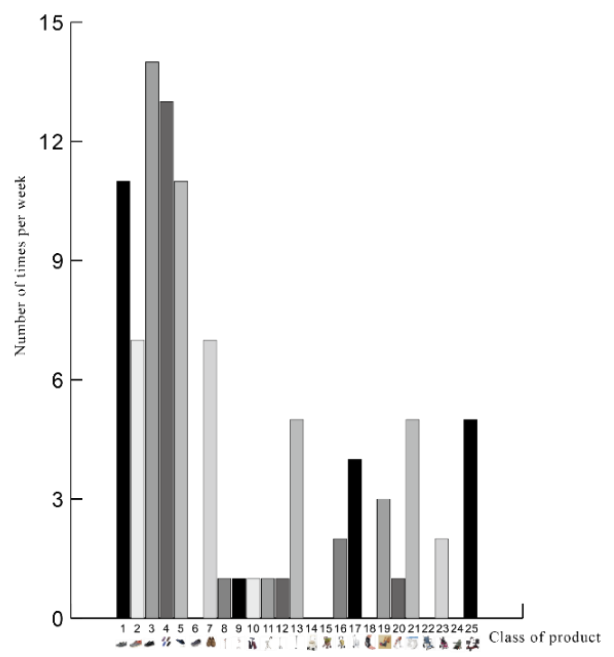

Fig. 5. Distribution of product usage from survey Fig. 6. Product use frequency from survey

According to the recruiting results from online questionnaire regarding the usage and frequency of use, 15 elderly were qualified as high-involvement users and were invited for in-depth EGM interview.

\section{Results and Discussion}


According to the interview with the high involvement user group, the results show that sample no.2, the anti-skid soft bottom functional shoes, is one of the essential style elderly would wear for going out, as shown in Fig. 7. It is believed that the protection of foot has been the important issue to the elderly. Many medical studies have pointed out that knee aging, plantar aponeurosis degeneration and other reasons will make elderly do not want to move around, which makes the elderly physical decline rapidly.

Among the 15 interviewee, according to their using experience and frequency of use, there are currently $60 \%$ of them wearing the very functional shoes, $20 \%$ wearing easy to wear and take-off ones. Only $20 \%$ currently not wearing functional shoes (Fig. 8), and nearly $80 \%$ of elderly people would choose functional shoes for the transport products. The results from the interviews also showed that about $48 \%$ of the elderly with the highest frequency of wearing functional shoes at about five days a week. (Fig. 9)
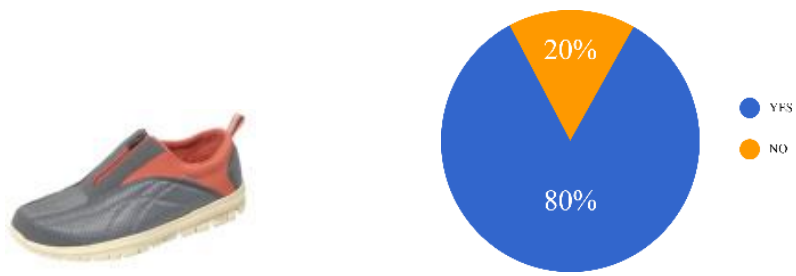

Fig. 7. Anti-skid soft bottom functional shoes Fig. 8. Usage of anti-skid soft bottom functional shoes

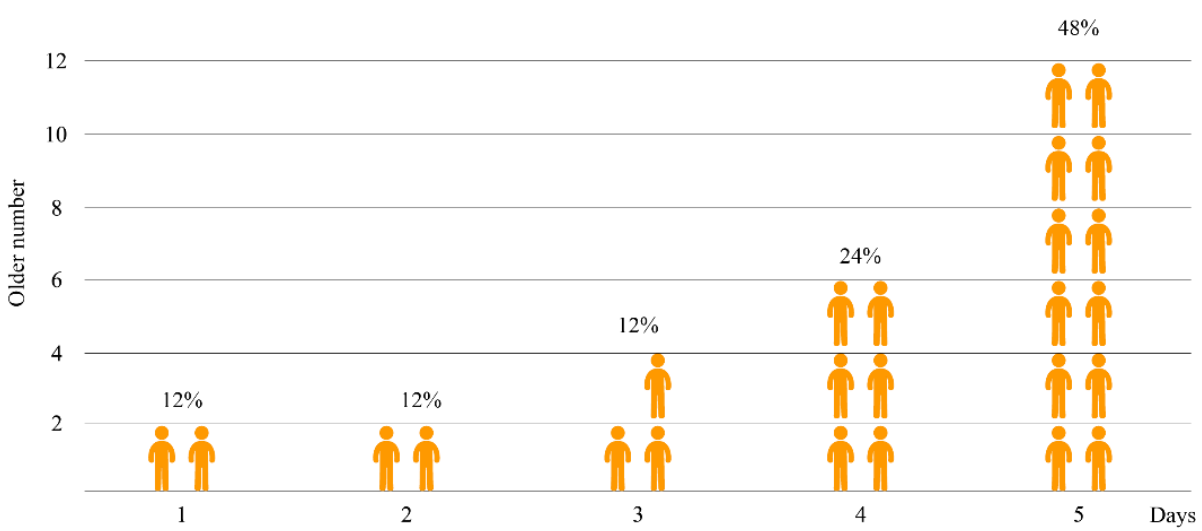

Fig. 9. Frequency of anti-skid soft bottom functional shoes used in a week

\section{Conclusion and Suggestion}

Concluded from the survey, data compiled, summarized and interview, it shows that the proportion of sales from mobile assistive and communication products is the highest. Which makes it clear what the demands of the elderly in the daily life are - hoping to move around independently, keep healthy, defer inconvenience caused by physical aging, and interact and communicate with friends and relatives, to maintain the quality of life. Among various functional products, footwear subcategory has the highest proportion within the transport products, which shows that footwear meets the basic functional needs of the elderly and is their most commonly used functional products. The results from the interview with 15 high involvement elderly also showed that footwear has the highest demand among functional products in daily use.

When designing functional footwear products for the elderly in the future, characteristic factors of the footwear must be captured and designed to meet the physical and psychological needs of different elderly groups. By doing so, it is hoped that functional products can be designed to meet the needs of users as we have wished in the very beginning.

Acknowledgements: The authors of this manuscript would like to thank Ministry of Science and Technology (MOST) of Taiwan for the financial support thru project number: 105-2221-E-214 -020 - 


\section{References}

[1] E. Dichter, "What is an image?" Journal of Consumer Research, 13, pp. 455-4721 1985.

[2] M. G. Gallarza, Gil Saura, and Calderón García, "Destination image towards a conceptual framework," Annals of Tourism Research, Vol. 29, No. 1, pp. 56-78, 2002.

[3] G. Kyle, A. Graefe, R. Manning, and \& J. Bacon, "Effects of place attachment on users' perceptions of social and environmental conditions in a natural setting," Journal of environmental psychology, 24(2), 213-225, 2004.

[4] C. F. Lee, and C. C. Kuo, "A pilot study of ergonomic design for elderly Taiwanese people," Proceedings of the 5th Asian design conference-international symposium on design science, Seoul, Korea, TW-030, 2001.

[5] P. Victor, Design for the real world: Human ecology and social change: Academy Chicago Publishers, Chicago, 2000.

[6] H. Murata, translated by Y. Huang, Consumer behavior in the super-aged society: Master the middle and senior citizens psychology, insight into the new trend of silver market, Taipei, EcoTrend Publications, 2015.

[7] M. Nagamachi, Kansei Engineering, Tokyo, Kaibundo, 1989. 